\title{
Analysis of the Latest Introductory Chinese Textbooks in Japan ---Based on the New HSK Syllabus
}

\author{
Jing Ge \\ North China University of Technology, No.5 Jinyuanzhuang Road, Beijing, China, 100144
}

\begin{abstract}
There are many Chinese textbooks with different levels, which are edited by Japanese publishers. However, compared with those edited in China, textbooks made in Japan are generally easier with more cultural introduction and vividly interesting illustrations. The author will make an analysis of Japan's recently published Chinese textbooks, which may be a direct reference to the writing of country-specific TCFL (Teaching Chinese as a Foreign Language) textbooks in China.

In this paper, 13 recently published introductory Chinese textbooks have been chosen to measure their vocabulary sizes, grammatical items and both Chinese and Japanese cultural elements. Meanwhile, the separate syllabus coverages of the vocabulary and grammatical items included in these 13 textbooks have be calculated based on the New HSK Syllabus (Level I, II \&III)
\end{abstract}

Index Terms - Japan; Introductory Chinese Textbooks; New HSK Syllabus; Coverage

\section{Introduction}

In recent years, along with the worldwide Chinese learning craze, the Chinese teaching in Japan has also grown vigorously. Compared with the small number of locally published Chinese textbooks in Western countries, there are diverse Chinese textbooks published in Japan every year that most Japanese learn Chinese with the locally published textbooks. According to Ref.[1], from 1978 to 2008, over 2100types of Chinese textbooks (extracurricular materials also included) were published in Japan, while since 2000, over 100 types of Chinese textbooks have been published every year.

Some scholars have made research on Chinese teaching and Chinese textbooks published in Japan (Ref. [2], [3] ,[4]). They all agree that due to Japanese universities' different teaching goals, the difficulty disparity between different Chinese textbooks is quite noticeable without a unified standard.

Since May, 2009, Hanban has implemented the New HSK, whose syllabus is of significant difference from the previous one. An in-depth research of the latest published textbooks based on the New HSK syllabus (Ref. [5], [6]. [7]) is necessary for a visual and quantitative evaluation of these textbooks. In this paper, the author calculated the amount of Chinese textbooks published in 2013 and 2014 by 10 important Chinese-textbooks presses in Japan ${ }^{1}$ and also analyzed 13 textbooks based on the New HSK Syllabus.

\footnotetext{
${ }^{1}$ Most textbooks in Japan are published in or before April, so those published on or before April $30^{\text {th }}, 2014$ are calculated as the data of 2014 . The data were calculated by the author from the presses' official websites.
}

Through the comparison, the author displayed the advantages and shortcomings of Japan's Chinese textbooks, hoping to inspire the writing of TCFL textbooks in China, especially the country-specific textbooks.

\section{Object of Study}

In this paper, the author conducted a survey of the textbooks published in 2013 and 2014 by 10 important Chinese-textbooks presses in Japan. In 2013, totally 39 types of textbooks were published while 36 in 2014. Most of the published textbooks are introductory and a small part are intermediate without advanced textbooks. According to the standard of a textbook for a year by one class ${ }^{2}$ a week or for a semester by two classes a week, the author picked out 13 types of introductory textbooks (6 in 2013 and 7 in 2014.) published in 2013 and 2014 by Asahi Press, Japan's largest press of Chinese textbooks. Based on calculation of the lessons, settings of the situational dialogues, text lengths, vocabulary sizes, grammatical items, and cultural introduction, the author analyzed the characteristics of Japan's recently published introductory Chinese textbooks and displayed their separate advantages and shortcomings.

\section{Characteristics of the Introductory Chinese Textbooks in Japan}

\section{A. Comparatively Lower Difficulty}

Compared with textbooks published in China, Japan's introductory Chinese textbooks published are much less difficult, with short lessons, 3-5 grammatical items and therefore much lighter burden. The lessons are closely connected with the practical life, with both Chinese and Japanese present. In the surveyed 13 types of textbooks, except Practical Chinese specifically about business Chinese for workplace freshman after graduation, other 12 textbooks are all about the daily used language. The conversations include all kinds of situations confronted by students, especially foreign students in their daily life, such as taking a taxi, dining in a restaurant, drawing money, shopping, mailing packages, and travelling. The longest lessons in these 13 textbooks have 15.5 sentences on average, while the shortest have only 5.2 sentences on average, with a length gap of 10 sentences. Despite the noticeable difference among the textbooks, the lessons are still much shorter than those of

\footnotetext{
${ }^{2}$ In Japan, a class lasts 90 minutes.
} 


\section{China's textbooks.}

\section{B. More Cultural Introduction}

As "TCFL means the systematic teaching of Chinese language and Chinese culture to foreigners and oversea Chinese" (Ref. [8]), the introduction of Chinese geography and culture is an indispensable part of Chinese textbooks. The cultural introduction will make the lessons more interesting, and further language learners' understanding of Chinese culture. In domestic TCFL, "most universities provide two types of courses: Chinese language and Chinese culture." (Ref. [9]), while these two types of courses are not separately provided in Japan due to the limited teaching resource and class hours. Therefore, most textbooks in Japan will introduce the cultural difference between China and Japan. According to the author's statistical data of the vocabulary about Chinese and Japanese geographies and cultures, 71 words are about China while 39 about Japan.

The most frequently used word of Chinese characteristic is "Beijing" with9 times, which is followed by "Roasted duck" with 7, "the Great Wall" with 6 and "Peking Opera" with 5. "Have the Spring Festival" and "Spring Festival" could be seen as the same cultural word and appear for 4 times. The most noticeable Chinese element is "Beijing", as most dialogues are set in Beijing. Similarly, the most frequently used word of Japanese characteristic is "Tokyo" with 9 times. It is followed by "yen" with 7 times, which is necessary for shopping. "Cartoon", both popular among Japanese and foreigners, appears 6 times.

The cultural introduction in the introductory Chinese textbooks in Japan includes both Chinese and Japanese cultures, which helps students introduce their own culture in Chinese, so as to promote communication between these two cultures. In their writing of country-specific TCFL textbooks, Chinese scholars could, besides considering language features, add the cultural introduction of the target countries. Introducing their own countries' culture in Chinese will make the students feel closer to and interested in the texts.

\section{Interesting Illustrations}

The recently published Chinese textbooks published in Japan all have many lovely illustrations, due to Japan's advanced Cartoon industry. Through the illustrations, learners have a visually direct impression of Chinese and Japanese related to the texts. A part about the Great Wall is accompanied by the illustration of the great construction, while the illustration of the Oriental Pearl and other iconic buildings will appear in the part of Shanghai. Texts with illustrations make the words vividly interesting.

\section{Shortcomings of Japan's Textbooks}

Chinese grade examination is a choice of the students' own, rather than a necessary graduation requirement of the Chinese major in Japan's universities. Therefore, universities' different teaching goals and the writing of the textbooks without a unified syllabus are now the most noticeable shortcomings of Japan's latest Chinese textbooks. In this chapter, the author will calculate the 13 textbooks' syllabus coverages in vocabulary and grammar, and then make a detailed analysis of their shortcomings.

\section{A. Vocabulary Coverage}

The author only calculated the 13 textbooks' coverages of the New HSK Syllabus (Level I, II, and III) in vocabulary and grammar. The following is the data about the vocabulary (Table 1):

Table 1 Vocabulary Size and the syllabus coverage

\begin{tabular}{|c|c|c|c|c|c|c|c|c|}
\hline & Textbook title & $\begin{array}{c}\text { Number of } \\
\text { words }\end{array}$ & $\begin{array}{l}\text { Number of Level } \\
\text { I vocabulary }\end{array}$ & Coverage & $\begin{array}{c}\text { Number of Level I } \\
\text { vocabulary }\end{array}$ & Coverage & $\begin{array}{c}\text { Number of Level I } \\
\text { vocabulary }\end{array}$ & Coverage \\
\hline 1 & Friends\&Chinese & 647 & 129 & $86 \%$ & 215 & $72 \%$ & 287 & $48 \%$ \\
\hline 2 & $\begin{array}{l}\begin{array}{l}\text { Chinese to the Test for } \\
\text { Freshmen }\end{array} \\
\end{array}$ & 471 & 76 & $51 \%$ & 154 & $51 \%$ & 224 & $37 \%$ \\
\hline 3 & Practical Chinese (Introductory) & 139 & 30 & $20 \%$ & 50 & $17 \%$ & 64 & $11 \%$ \\
\hline 4 & $\begin{array}{l}\text { Learn Chinese Anytime and } \\
\text { Anywhere }\end{array}$ & 526 & 122 & $81 \%$ & 207 & $69 \%$ & 268 & $45 \%$ \\
\hline 5 & Blossom of Chinese & 624 & 114 & $76 \%$ & 197 & $66 \%$ & 284 & $47 \%$ \\
\hline 6 & Chinese Learning & 351 & 83 & $55 \%$ & 136 & $45 \%$ & 159 & $27 \%$ \\
\hline 7 & Remember Chinese & 668 & 137 & $91 \%$ & 236 & $79 \%$ & 325 & $54 \%$ \\
\hline 8 & New Basic Chinese & 353 & 144 & $96 \%$ & 283 & $94 \%$ & 292 & $49 \%$ \\
\hline 9 & Progress in Chinese Learning & 610 & 114 & $76 \%$ & 195 & $65 \%$ & 281 & $47 \%$ \\
\hline 10 & $\begin{array}{lll}\text { Challenge! } & \text { Chinese } & \text { for } \\
\text { Freshman } & & \\
\end{array}$ & 447 & 115 & $77 \%$ & 193 & $64 \%$ & 255 & $43 \%$ \\
\hline 11 & New Chinese Trip & 670 & 124 & $83 \%$ & 201 & $67 \%$ & 275 & $46 \%$ \\
\hline 12 & Simple and Practical Chinese & 174 & 47 & $31 \%$ & 93 & $31 \%$ & 104 & $17 \%$ \\
\hline \multirow[t]{2}{*}{13} & $\begin{array}{ll}\text { Sino-Japan } & \text { Cultural } \\
\text { Communication Square }\end{array}$ & 665 & 116 & $77 \%$ & 200 & $67 \%$ & 279 & $47 \%$ \\
\hline & Average & 488 & 104 & $69 \%$ & 182 & $61 \%$ & 238 & $40 \%$ \\
\hline
\end{tabular}


The 13 textbooks have obviously different vocabulary sizes, with the smallest of 139 words and the largest of 670 ones. The average vocabulary of these 13 textbooks is 488 words, very close to Level III's requirement of 600 words. In vocabulary, the average of Level I is $69 \%$, that of Level II is $61 \%$ while that of Level III is as low as $40 \%$. In other words, despite some textbooks' meeting Level III's vocabulary requirement of 600 words, their overall coverage of the syllabus is still very low.

The reason of the comparatively low syllabus coverage is the large number of homographs, which are not completely new words to Japanese students and also, the vague teaching goals. Another important reason is the cultural introduction. Through comparison, the author discovered that the culturally feature words are in proportion to the textbooks' vocabulary sizes. To display the cultural difference, as well as to inspire the Chinese learners' interest will definitely expand the vocabulary size and grammatical items. Therefore, the lack of syllabus in the textbook writing and the need of increasing interest will certainly mean the lower syllabus coverage.

\section{B. Coverage of Grammatical Items}

Section 4.1 compared all textbooks' vocabulary sizes with the syllabus and in this section, the author will calculate the 13 textbooks' grammatical items and analyze their syllabus coverage. According to the author's calculation, there are 34 Level Igrammatical items, 73 Level II and 122 Level III. The detailed coverages are as follow (Table 2).

Table 2 Syllabus coverage in grammar items

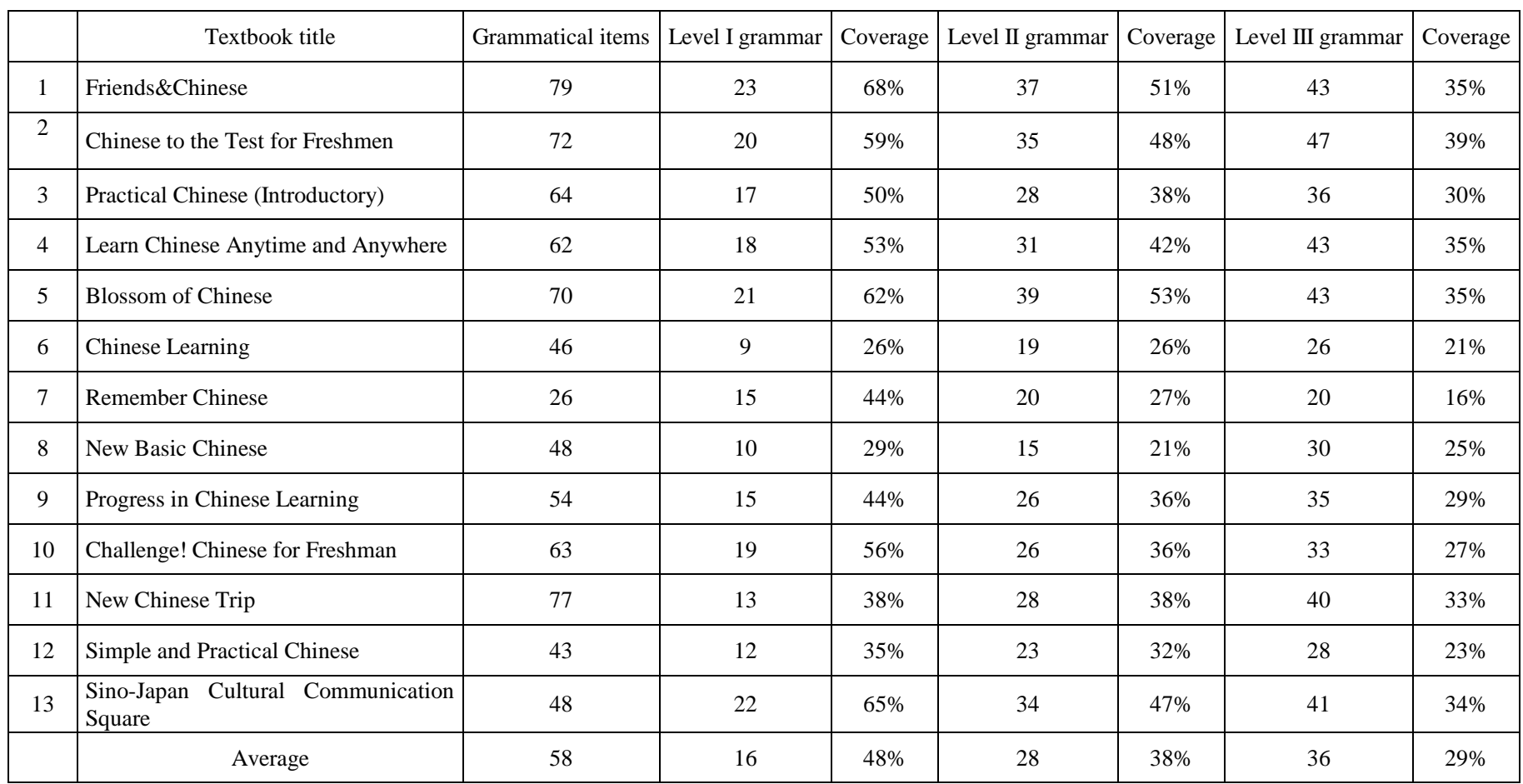

The surveyed 13 textbooks have 58 grammatical items in average, with the largest amount of 79 and the smallest of 43 . The average is in the middle of the requirements of Level I and II. According to Table 8, the textbooks' syllabus coverages in grammatical items are comparatively low: only 6 textbooks' coverages of Level I are over $50 \%$, the highest $68 \%$, the lowest $26 \%$ and the average $48 \%$. The coverage of Level II and III are even lower, as the average coverage of Level II is $38 \%$ with only 1 book having an over $50 \%$ coverage and the average coverage of Level III is $29 \%$ with the lowest being $16 \%$ and no book is over $50 \%$. Compared with the coverage in vocabulary, that in grammar is further lower.

\section{Conclusion}

The TCFL writing in China has a history of 60 years. While "the writing is gradually country-specific and diverse with the support of multi-media", "the truly country-specific textbooks and international cooperation are still inadequate". (Ref. [10]). Japan's Chinese textbooks could be regarded as "country-specific" and these textbooks of different types are written through "Sino-Japan cooperation". The analysis of the advantages and shortcomings of Japan's Chinese textbooks could function as a practical reference for the "countryspecific" TCFL textbooks by Chinese scholars.

\section{Reference}

[1] Tsuda, Ryo, "An analysis of Chinese Teaching Material in Japan", Chinese Language Learning, No.2, pp105-112.Apr 2010.

[2] Rujie, Shi, "Chinese textbooks in Japan and the introduction of their publishing", Chinese Teaching in the World. No.2.pp105-109. Apr 2004.

[3] Chungui, Guo, The Chinese education in Japanese universities, Chinese Teaching in the World.No.4, pp91-97. August 2005.

[4] Ying, Zhang, Chinese textbooks in Japan and Analysis, Chinese 
Study.No.3, pp.61-69.June 2001.

[5] Hanban/ Confucius Institute Headquarter (Ed.), New HSK Syllabus Level I, Beijing: the Commercial Press, 2011.

[6] Hanban/ Confucius Institute Headquarter (Ed.), New HSK Syllabus Level II, Beijing: the Commercial Press, 2011.

[7] Hanban/ Confucius Institute Headquarter (Ed.), New HSK Syllabus Level III, Beijing: the Commercial Press, 2011.
[8] Tang, Cheng, "On the several issues in current TCFL", Language Teaching and Study. No.3.pp4-18, Mar 1992.

[9] Guanglei, Chen, On the issue of cultural teaching in TCFL, Applied Linguistics. No.1, pp23-26.Jan 1997.

[10] Xiaobin, Yang. The achievement and problems of TCFL writing in China, Hubei University Journal (Philosophy and Social Science Section). No.38-4, pp31-34, 2011. 